\title{
THE CONTRIBUTION OF TEACHING LOGIC TO ETHICAL DECISION MAKING
}

\begin{abstract}
Everyone makes many important decisions in one's life and these decisions are the result of one's thinking. However, in many critical situations one cannot find a solution. The paper deals with the importance of teaching logic in mathematics for the human individual to be able to make ethically correct decisions. The mathematical formalism can simplify thinking and thus achieve the proper conclusion. Teaching logic can help humans learn the basic rules of logical reasoning. Mathematics is essentially a universal language of physics and technology but it can also be a language of communication in ethics. The unambiguity of mathematics could be used to solve many controversial ethical issues in the application of new scientific knowledge.
\end{abstract}

Keywords: Logic, ethical decision making, a pupil, opinion.

\section{Introduction}

Human beings are the only species that act rationally in a conscious way, are able to derive new knowledge from known ones, are able to anticipate and plan their actions. Rationality of man lies in the ability to think and act in ways that are led by logic. Logic is characterised as an analysis of methods used in human thinking or reasoning. It is necessary to develop the human ability to think. The school is the natural environment for the development of all aspects of the human personality, and, therefore, also of his thinking. Man in himself has the ability to think and he has the opportunity, and in a sense the obligation, to improve it during the educational process. Students should realise, with the help of a teacher that developing the ability to think logically is worth more for their future than just receiving information from individual subjects. Developing of thinking is the preparation for their future adult life, where they are expected to make responsible and correct decisions. These decisions are more or less connected to human being and carry within themselves an ethical dimension. Ethical decision-making process is based on the ability to assess conflict between two or more values of ethically relevant factors and, after careful consideration, choose the solution of the conflict. Every athlete spends a lot of time training that is, repeating the same activities. The athlete trains, because he knows that only diligent training is good preparation for the real game. School represents very important training for everyone. Every young person wants to be successful in his/her life. This should be a strong internal motivating force to spend time at school meaningfully. It means not only to receive information, but also to think over it. Young people, students, should be aware that if they spend time doing something with interest, they can achieve the best results. And this statement is true also in the case of mathematics. Its priority (given its abstractness) is to develop pupils' thinking. For example, Blais Pascal, at the age of 12, built the foundations of geometry with its own terminology. For a line he used the term stick, for a circle the term wheel. His father, a keen mathematician, took care of the son's best mathematical education at that time. The son soon began to achieve excellent results. But Pascal departed from the science after the miraculous rescue of his life and he said about mathematics: "Mathematics is the most difficult job for the brain. I call it the most beautiful craft in the world, but after all it is only a craft. It's good for us to develop the force, but not to use that force" [1]. But he denies that claim by his own contribution to human progress. His brain was cultivated by mathematical means. He was a great humanist. He used his mathematical education to make human effort easier. He constructed a wheelbarrow, omnibus project, and as an 18-year old boy he constructed a calculating machine for finance officers in his father's office. The example of this well-known not only mathematician can illustrate the impact of mathematics education to his way of thinking. He developed the strength not of muscles but of his mind thanks to the study

\footnotetext{
* 'Dalibor Gonda, ${ }^{2}$ Petr Emanovsky

${ }^{1}$ Department of Pedagogical Studies, Faculty of Humanities, University of Zilina, Slovakia

${ }^{2}$ Department of Algebra and Geometry, Faculty of Science, University of Palacky, Olomouc, Czech Republic

E-mail: daliborgonda@fhv.uniza.sk
} 
of mathematics. He used the strength of his mind for the good of other people. Retrospectively, mathematics strongly influenced his ethical behaviour. The aim of this paper is not to be a guide of teaching mathematical logic. In the first part we focus on the potential contribution of mathematics to solving tasks that life itself brings us. Subsequently, in the second part we focus on the preventive role of mathematics to the most common errors leading to incorrect attitude or decision.

\section{The contribution of mathematics when considering the problem}

Everyone has already met with puzzles. An interesting thing is that although we know the text of the puzzle, often we do not remember its solution, even though we had already heard it. This fact can be used as an argument confirming the truism: "Give a man a fish and you feed him for a day; teach a man to fish and you feed him for a lifetime." In our case, if we teach students to conclude correctly during the math course, we develop their ability to correct and independent decision making as well. Teaching logic can be based on solving the known puzzles. Our priority, however, will not be to solve the puzzle, but to focus on learning the correct thinking and reasoning in finding a solution. A puzzle will be used as an appropriate motivating factor. When solving logical puzzle, the teacher acts as a moderator in searching a solution.

Logic puzzle: The way out of the maze

We have been wandering through the maze a long time, we are tired and hungry. Our last hope is the two brothers at a crossroad. However, we can ask only one yes/no question. The problem is that one of them always tells the truth and the other is a notorious liar (always lies), and we do not know who is who. What question should we put to find out the way to the exit of the maze?

Solution: After setting the puzzle, students will suggest many solutions. We recommend the teacher to wait until the students exhaust all their solutions and afterwards the teacher can guide their thinking. First of all, the teacher turns their attention to the limit of puzzle setting: "We have only one yes/no question." All students' questions that are not yes/no ones are incorrect. As with mathematical calculations also when reasoning there must be the solution in strict accordance with the puzzle setting. Finding the solution must start with puzzle set analysis. We do not know which brother is a liar and which is the truth-teller but both of them seem to know the way out of the maze. We need to find such a question to which the answer of any of the brothers will show us the way out. We look for the question, according to which we learn what we need, irrespective of which of the brothers will respond. Since we have only one question we cannot figure out which of the brothers is the truth-teller and which is the liar. The question must be focused on finding the right way out of the maze. One of such possible questions is: "What would your brother say if we asked him whether the right road leads out of the maze?"

The following is an analysis of the brothers' responses at a crossroad. The analysis will help us to validate the accuracy of the found solution. If we ask the truth-teller, he only reproduces the incorrect answer of his brother "liar". So his answer would have marked the right way incorrect. If we asked the liar, he would have "distorted" his brother answer and indeed he would mark the right way as incorrect. Both brothers mark the right way as incorrect, therefore, it does not matter which brother we ask our question. After their answer we know that we must move in the opposite direction to the right direction according to the brothers.

To find the right solution (the question for both brothers) and to watch the validation of question correctness is demanding for most students and not only for them. We often hear the sentence: "I got lost!" This situation, in the introduction of the teaching of logic, can be used to define the basic concepts of propositional logic - proposition, negation, the true value of proposition, propositional form. The use of those terms will help us to solve the puzzle "mathematically". Mathematisation lies in the fact that the individual thought processes are written symbolically. The task solution will be, in fact, "illustrated".

At the beginning, we agree that the way to the left leads out of the maze (brothers know about it, but we do not). The replies of the truth-teller will be indicated by the symbol, the liar's responses by symbol. What would be the outcome after a natural question?

Does the way to the left lead out of the maze?

We can see that the question will not help us to get out of the maze, because the truth value of the brothers ' replies depends on which one we ask. We would get such different responses (and their truth values) to the question: Does the way to the right lead out of the maze? We, however, look for such a question, where would be true for the truth values. Our task is to change the question as to alter the truth value of only one of the statements or. It is not intended to change the answer of one of them, but to change the truth value of reply of one of them. To solve the puzzle we need to realise that truth-teller repeats the answer of his brother without any change and the liar tells us the opposite of what his brother would say. The liar negates his brother's answer, so that he will also change its truth value. After the question

What would your brother say if we asked him if the way to the left leads out of the maze?

we get the following result

It is clear from the scheme that we have found the right question. Its truth value is independent of which brother responds. At the same time we can see the response of the two brothers has the truth value 0 , because the truth value of the answer is determined by the way out of the maze. Therefore, we must do the opposite as we were said, we will use the way to the left. In the end, on the defence of the truth-teller, we need to say that he 
does not deceive us, just repeats the answer of his brother. On the contrary, if his brother's answer changed from false to true, then he would deceive us.

We think that the solution of the logical puzzle is a viable way how to "peacefully" bring students into mathematical consideration. "Mathematical" solution is in itself an important element of illustration. Significant results of considerations are clearly shown and we can return to them at any time, without re-reading connected text. At the same time there is no need to remember the whole train of thought of the solution. Our attention in the "mathematical" solution was drawn to the truth value of brothers' 'replies.

We just edited the question so that we will get the desired truth value of brothers' response. The students will acknowledge that the introduction of mathematics simplified and clarified the puzzle solving. Students find it surprising that the very question that should be the solution of the puzzle in "mathematical" thinking is not assessed. We do not pay primary attention to it, because it is not a proposition. The question is only edited and the brothers' replies, that are propositions, are examined.

It is known that propositional logic deals with reasoning depending only on truth values of propositions, leaving the internal structure of the propositions out of account. This approach can be quite difficult for students. Their thinking is shifting to a higher level. Propositional logic gives us some scheme that allows us to navigate easier when deciding about the correctness or incorrectness of a proposition. Students learn that when they decide for something it is not always essential who and how to say it. It is often essential what the truth value of elementary propositions that compose a proposition is. In this way, students are trained to cope with different ideologies.

\section{A healthy common sense is not always enough}

In general, mathematics is considered the least favourite subject, and the propositional logic the least popular thematic unit. Mathematics and the propositional logic too, are often reputed to be out of students' lives. They often ask: "What do I need it for, when will I use it in my life?" It is hard to convince them that they will use in life the truth value of the proposition

If it is raining, then the car is green.

We suppose that in teaching any of the themes it is necessary to keep the detached view and keep in mind the main objective of teaching mathematics - development of logical thinking. Especially in teaching logic there is the space to convince students about the need to develop their ability to consider properly and make decisions. First of all, it is necessary to convince students that it is possible to learn how to think logically. Prerequisite for learning logic is a spontaneous person's ability to think in accordance with certain rules and laws. Each person must in one's life think over what they hear and evaluate whether it is true or not. One will often draw new knowledge based on the obtained "information". Every person has to make a lot of vital decisions and everyone wants to make correct decision [2]. Teaching logic (and mathematics itself) is not a challenge for students to deal with something new. On the contrary, it is a challenge for a new perspective of their daily activities. It's an offer to make finding the right decisions easier. Everyone has the ability to think. Like any other ability, also the ability to think can be developed by training, in this case by thinking. If, within training, the new elements are added, thinking shifts to the next level. Thus, if students involve mathematical elements into their way of thinking, it can be simplified and clarified. As an analogy we can mention a person walking on the ice. Walking on the ice is more demanding than walking on dry land but it is still possible. Over time, training and considering what to do to improve, one learns that it is necessary to make small steps and walk more slowly. If we give a person skates, this person will not believe that the skates are more convenient for walking on the ice than normal shoes. But this individual will be getting better at skating so he will realise that skating is common activity for him. And at the same time it will become clear that skating is a more convenient way to move on the ice. In the end we would like to note that the skates are the result of thinking of their discoverer about the options for a better movement on the ice. As we can walk down on the ice in shoes, so we can also engage in intellectuall reflection. But it would be possible to improve our thinking, to move to a higher qualitative level of teaching logic in mathematics.

One does not like to let anybody to interfere in his/her internal world. Students often use the counter-arguments, the sufficiency of the quality of their thinking. They say "the common sense is enough for me." The common sense can be considered as reflection on the observation of laws around the world and events around us. In a sense this is a natural logical intuition, and one makes one's judgments and decisions based on this intuition. But in many critical situations, common sense cannot find a solution and even can offer the wrong solutions [3]. For example, the observation of man leads to the following statement

If a subject moves, it means there is a force having an effect on it.

Isaac Newton, however, claims that a subject can move without the application of external force and in uniform rectilinear movement.

We face two opposing arguments concerning the same subject. Can both be true? Basically, we come to the problem: everyone is right. We suppose it is a serious problem that undermines human relationships in society and even within families. "Everyone has one's own truth" is a phenomenon that divides society and often also causes family breakdown. A law of negating a logical dispute should be instilled in students during logic lessons: two contradictory claims, concerning the same subject matter, cannot be true simultaneously. In this way students will know that in this case it is necessary to seek the truth. The 
situation will not divide the participants. Instead, it becomes an invitation to a common search for truth. A joint effort connects. In the first year of secondary school students still do not make many important decisions. But school is (should be) a preparation for life, it should be beneficial to further improvements of future life. Each of the students will have to do a lot of judgments and decisions and their quality, to a significant extent, depends on the contribution of the logic teaching and mathematics in general [4]. The students should take an important lesson from logic teaching: the truth is only one and does not depend on me. This brings us to the ethical dimension of decision making process.

Of course, it is possible to say a lot of compatible arguments about the same thing, e.g. .:

The dog is small. The dog is black. The dog is young.

These arguments are logically consistent, because there may be a small, black, young dog. Even these arguments are logically consistent:

It seems to me that the dog is black. It seems to me that the dog is brown.

The two statements can be true and it does not concern the colour of the dog but if a person finds it true or not. In such examples, the students learn that before they consider whether someone is telling the truth or lying, firstly it is necessary to consider what the person wants to say. There is a big difference if someone says:

It seems to me that the task is solved correctly. (1)

or says:

That task is solved correctly. (2)

The veracity of the first statement (1) does not depend on whether the task is solved correctly or incorrectly. The second statement (2) is true only if the task is solved correctly.

The students should gradually realise that judgments are formed from the opinions and the opinions are made up of concepts. The concepts are represented by words that are the cornerstone of our expressing, as well as the source of many errors. These errors are due to the fact that there may be confusion of concepts that are expressed by the same or very similar words. This is a homonymy. Homonyms may be the seeds of many logical errors as well as disputes between people. These errors can be prevented when both sides hearing the same words think about the same concepts. Correct and accurate defining of concepts, which are being discussed, can limit to a large degree the amount of unnecessary misunderstandings. And this is the big role of mathematics as an exact science. From learning mathematics, students take the knowledge that a fair solution of the problem must be based on the precise definitions of (mathematical) concepts. In this context, the confusion of the term (the word) with what it means is not always detectable mistake [5]. The known sophism illustrates it:

If you say something, it goes through your mouth. Are you talking about the car, so the car is going through your mouth.
In the sophism there is apparent word confusion (and what the word refers to). This kind of errors in reasoning, however, becomes less clear, if a mentioned subject is highly abstract. In the study of geometry we often identify a sign of point (e.g. on the blackboard, in the workbook, etc.) with a point itself. A sign of point has non-zero size but the point in geometry is dimensionless. A sign of point was arranged at the request for graphicness that the interpretation of the curriculum was not just in the abstract level. It should be mentioned that the concepts have different names in different languages, and these names were essentially attributed to them by the concept "agreement". When we learn a foreign language we do not learn the new concepts. The concepts, which we already have created, are only assigned the common names in a particular language. Similarly, it is almost the same when learning mathematics. Already known concepts are assigned the mathematical symbols, we do mathematical operations with the already known concepts.

Another source of logical errors, thus misunderstanding and disputes too, is the failure to differentiate between concepts and objects that fall under these objects. Such errors are made frequently in everyday life situations. The concept is an abstracted and generalised form of objective reality by thinking. It should be understood that the dog is only the concept in our mind. Realistically there is only a concrete dog as an object. A dog would not protect us from thieves. But the dog, which we have at home, would. At the same time it is necessary to teach students to distinguish between the content of the concept (set of features) and range of the concept (subjects that fall under the concept). The students should be alerted about the existence of contentempty concepts. Content-empty concepts exist because they are logically questionable (square circle) or imaginary (gingerbread house) or they represent ideal objects (absolutely black body). Although they are content-empty, it is possible to work with them in reasoning and even in science - absolutely black body in physics. Mathematics is regarded as a purely abstract science. But from the text described above it can be seen that our ordinary speech in its abstractness does not lag behind mathematics [6].

In reasoning, there is an important role of images that are linked with the concepts. Each idea is a unique psychic act. A person creates his own image about the concept. When you say the word "dog" not everyone imagines the same dog. These concepts are subjective in nature and as a whole are impossible to talk about. As people are different so are their ideas. In contrast, the concepts are not owned by individual people. The terms do not change according to the fact that they are recognised by people. They are outside our thinking. One can even say that the concepts have their logical existence, irrespective of whether someone thinks them or get to know them. Prejudices are closely linked with the images connected to the concepts. Then these prejudices can influence human behaviour to their surroundings. It is sufficient for a child to have a negative experience with a dentist and for years the concept of a dentist will be associated 
with the concept of pain. On the basis of prejudice, we can all, falling within the concept, "lump together". A belief can be developed from the prejudice, and such belief will direct our decision at the wrong direction. Many ideologies work this way. First, they create the prejudice against a certain group of people and later the conviction that they are the enemy. A person can manage to defend oneself, but only if one retains the ability of independent and free thinking that was conscientiously developed during one's student days.

\section{Conclusion}

Mathematics is often considered the queen of all sciences. We think the queen is good only if it is there for all and serves all. During teaching logic, there is a large space for the formation of a correct students' attitude towards mathematics. If they realise that they do not learn mathematics to know how to solve the complex equations, but the real reason for learning mathematics is that it will assist them in dealing with life's challenges. This point of view will change their attitude towards mathematics. Thanks to mathematics their daily activity - thinking, becomes a more efficient and more accurate activity. They realise that an advanced thinking causes that they know much more than they have learned. They are capable of drawing new findings from already acquired knowledge. They will be able to answer the questions that even lead away from that knowledge. They will have the ability and the courage to express their opinions and at the same time will be able to defend their views with the right arguments. Advanced thinking as the result of learning mathematics gives students the opportunity to retain freedom of thoughts and making decisions in adulthood. Nowadays, young people quite often postpone important decisions (choice of college, marriage, and parenthood) for later or have others make them for them. In accordance with moral determinism they try to choose the greater good of the alternative options. They postpone making decisions, they do not know on what basis they have to decide. They face the danger of "Buridan donkey", which died of starvation between two identical hay piles, wondering which was better. The students know from the maths classes that the task can have more solutions and all solutions are equal. But they learn something more. Although the two sub-tasks have equivalent solutions, their use in the search for general solutions may lead to different results. One of them can be more acceptable to us than the other. Thus, having a look "into the future" will help us to choose the equivalent options the one that leads us to the most desired solution. Mathematics serves man perfecting his daily activities - thinking and decision making. If we can instil this belief in students mind, they will be willing to train their mind in mathematics classes and also make courageous, therefore, correct ethical decisions in adulthood.

\section{References}

[1] ZNAM, S. et al.: View into the History of Mathematics (in Slovak), Alfa : Bratislava, ISBN 978-80-87053-16-4, 1986.

[2] TUREK, I.: Didactics (in Slovak), Iura Edition : Bratislava, ISBN 978-80-8078-198-9, 2008.

[3] GAHER, F.: Logic for Everybody, IRIS : Bratislava, ISBN 80-89018-54-8, 2003.

[4] ZELINA, M., ZELINOVA, M.: Development of Creativity of Children's and Youth's (in Slovak), Bratislava : SPN, ISBN 80-08-00442-8, 1990.

[5] FULIER, J., SEDIVY, O.: Motivation and Creativity in Mathematical Education (in Slovak), Prirodovedec : Nitra : FPV UKF, ISBN 80-8050-418-0, 2001.

[6] HEJNY, M. et al.: Theory of Mathematical Education II (in Slovak), SPN : Bratislava, ISBN 80-08- 00014 -7, 1989. 